\title{
Karakteristik Pekerjaan, Quality Of Work Life Dan Kepuasan Kerja Terhadap Organizational Citizenship Behavior (Ocb) Pada Pt Djasa Bahari Di Surabaya
}

\author{
Titin 1, Yunni Rusmawati DJ², Luluk Nur Azizah ${ }^{3}$, \\ Fakultas Ekonomi Universitas Islam Lamongan ${ }^{1,2,3}$ \\ titin@unisla.ac.id ${ }^{1}$, yunnirusmawati@unisla.ac.id ${ }^{2}$, \\ luluknurazizah@unisla.ac.id ${ }^{3}$
}

\begin{abstract}
Abstrak: Sumber daya manusia merupakan aspek penting dalam kemajuan pada suatu organisasi yang tidak dapat terpisahkan dari sebuah manajemen perusahaan. Pengetahuan dan skill dari sumber daya manusia sebagai pelaksana yang handal dalam fungsi-fungsi organisasi. Keberhasilan perusahaan bergantung pada sumber daya manusia sebagi aset yang harus dikembangkan dengan baik. Keyakinan bahwa karyawan yang dapat merasakan kepuasan dalam bekerja akan membawa dampak yang baik bagi perusahaan sehingga kepuasan kerja merupakan faktor penting yang harus diperhatikan oleh sebuah perusahaan. Perusahaan mengharapkan perilaku yang diciptakan oleh karyawan menjadi tuntutan organisasi tidak hanya perilaku in role tetapi juga perilaku estra role yang disebut Organizational Citizenship Behavior (OCB). Metode pengumpulan data menggunakan kuesioner yang diisi secara lengsung oleh responden. Alat analisis data yang digunakan dalam penelitian ini adalah regresi linier berganda. Hipotesis pada penelitian ini menunjukkan bahwa karakteristik pekerjaan berpengaruh positif terhadap organizational citizenship behavior, adapun hipotesis kedua yaitu kepuasan kerja berpengaruh positif terhadap organizational citizenship behavior dan hipotesis yang ketiga yaitu Quality of Work Life berpengaruh positif terhadap organizational citizenship bevavior. Obyek penelitian pada PT Djasa Bahari di Surabaya yang bergerak di Ekspedisi Ekspor Import.

Kata Kunci : Karaktersitik Pekerjaan, Quality of Work Life, Kepuasan Kerja, Organizational Citizenship Behavior
\end{abstract}

Sumber daya manusia merupakan penentu dalam strategi dan kebijakan manajemen pada suatu perusahaan di era globalisasi ini. Dalam hal keberhasilan dan kefeefektifan suatu perusahaan sangat bergantung pada kualitas sumber daya manusia dengan kualitas kinerja yang sudah diberikan kepada perusahaan. Kepuasan kerja dari karyawan dan komitmen organisasi yang tinggi merupakan faktor dalam organisasi yang menimbulkan Organizational Citizenship Bahavior (Robbin \& Judge, 2007). Turnover merupakan faktor penentu dalam loyalitas dan kepuasan kerja dalam suatu perusahaan. Semakin tinggi tingkat turnover pada perusahaan merupakan tantangan khusus bagi pengembangan sumber daya manusia dikarenakan tidak dapat diprediksi. Melatih karyawan pengganti itu membuat hilangnya waktu dan biaya dari organisasi yang membuat pengaruh yang kurang baik (Nanggoy dan Harianti, 2005). Dari fenomena diatas dapat disimpulkan bahwa perlunya perusahaan dalam hal fokus pada karakteristik pekerjaan, Quality of Work Life dan Kepuasan kerja sehingga karyawan dapat memberikan konstribusi yang maksimal kepada perusahaan. Diketahui dari hasil survei pra penelitian penulis tertarik untuk meneliti mengenai Quality of Work dalam Organizational Citizenship Behavior di perusahaan PT Djasa Bahari di Surabaya karena 
melihat fenomena banyaknya karyawan yang sering di mutasi ke cabang lainnya dan banyaknya turnover pada perusahaan.

Organizational Citizenship Behavior (OCB) terdiri dari kinerja yang mendukung lingkungan sosial dan psikologis tempat pelaksanaan tugas berlangsung (organ, 1995). Sejumlah penelitian telah menunjukkan bahwa ketika karyawan terlibat dalam Organizational Citizenship Behavior (OCB), misalnya menjadi sukarelawan untuk tugas-tugas tambahan terkait pekerjaan, membantu rekan kerja menangani beban kerja yang berat berpartisipasi dalam aktivitas yang tidak diperlukan tetapi dianggap penting bagi organisasi) mereka meningkatkan efisiensi dan efektivitas organisasi mereka (Podsakoff dkk, 2009). Selain itu karakteristik pekerjaan pada $O C B$ memberikan dampak karakteristik pekerjaan misalnya otonomi pekerjaan, variasi keterampilan dan konflik peran pada organisasi.

Perilaku organisasi kewarganegaraan muncul disaat kinerja sumber daya manusia tinggi dimana pekerjaan yang dimiliki oleh masingmasing individu dapat efektif sebagai penjelasan situasi dan perancangan suatu pekerjaan yang disebut dengan karakteristik pekerjaan (Krietner \& Kinicki, 2004). Pada penelitian Sehana (2015) menyatakan kualitas kehidupan kerja (Quality of Work Life) berpengaruh positif terhadap Organizational Citizenship Behavior sedangkan Syahbanuri \& Abdurrahman (2019) kualitas kehidupan kerja tidak berpengaruh secara signifikan terhadap perilaku organisasi kewarganegaraan. Tujuan penelitian ini adalah untuk menganalisis pengaruh karakteristik pekerjaan, Qualiti of Work Life dan Kepuasan Kerja Terhadap Organizational Citizhenship Behavior (OCB).

\section{METODE PENELITIAN}

Peneliti menggunakan deskriptif kuantitatif sebagai metode ilmiah (scientific) karena telah memenuhi kaidah-kaidah ilmiah yaitu konkrit/empiris, obyektiif terukur, rasional dan sistematis. Metode ini juga disebut dengan discovery karena dengan motode ini dapat ditemukan dan dikembangkan berbagai iptek baru. Metode ini disebut metode kuantitatif karena data penelitian berupa angka-angka dan analisis menggunakan statistic (Sugiyono, 2017). Populasi pada penelitian ini sejumlah 60 orang untuk di cabang Surabaya. Teknik sampling pada penelitian ini menggunakan metode sampel jenuh sehingga jumlah sampel sebanyak 60 orang.

\section{HASIL DAN PEMBAHASAN}

\section{Korelasi Berganda}

Analisis korelasi bertujuan untuk mengetahui hubungan dua variabel atau lebih. Jika trdapat dua variabel di sebut korelasi sederhana, tetapi jika lebih dari dua variabel di sebut korelasi berganda (Priyatno, 2013). Dalam perhitungan korelasi akan didapat koefisien korelasi, 
koefisien korelasi ini digunakan untuk mengetahui keeratan hubungan, arah hubungan, dan berarti atau tidaknya hubungan tersebut.

Tabel 1

Hasil Pengujian Korelasi Berganda Model Summary

\begin{tabular}{|l|c|r|r|r|}
\hline Model & $\mathrm{R}$ & $\begin{array}{c}\mathrm{R} \\
\text { Square }\end{array}$ & $\begin{array}{l}\text { Adjusted R } \\
\text { Square }\end{array}$ & $\begin{array}{c}\text { Std. Error } \\
\text { of the } \\
\text { Estimate }\end{array}$ \\
\hline 1 & $0.923^{\mathrm{a}}$ & 0.851 & 0.843 & 1.260 \\
\hline
\end{tabular}

a. Predictors: (Constant), X3, X1, X2

Sumber : data lampiran diolah dengan SPSS 21, 2021

Berdasarkan hasil uji kolerasi ganda pada tabel 1, hasil analisis kolerasi ganda menunjukkan bahwa hubungan antara variabel terikat $(\mathrm{Y})$ yaitu Organizational Citizenship Behavior (OCB) dengan variabel bebas $(X)$ yaitu Karaktersitik Pekerjaan, Quality of Work Life dan Kepuasan Kerja secara bersama - sama adalah sebesar 0,923 atau 92,3\%. Hal ini menunjukkan bahwa hubungan yang terjadi antara variabel terikat (dependen) dengan variabel bebas (independen) adalah kuat.

\section{Regresi Linier Berganda}

\section{Tabel 2}

Uji Regresi Linier Berganda

Coefficients $^{\mathrm{a}}$

\begin{tabular}{|c|c|c|c|c|c|c|c|c|c|c|}
\hline \multirow[t]{2}{*}{ Model } & \multicolumn{2}{|c|}{$\begin{array}{l}\text { Unstandardi } \\
\text { zed } \\
\text { Coefficients }\end{array}$} & \multirow{2}{*}{$\begin{array}{c}\begin{array}{c}\text { Standar } \\
\text { dized } \\
\text { Coeffici } \\
\text { ents }\end{array} \\
\text { Beta }\end{array}$} & \multirow[t]{2}{*}{$T$} & \multirow[t]{2}{*}{ Sig. } & \multicolumn{3}{|c|}{ Correlations } & \multicolumn{2}{|c|}{$\begin{array}{c}\text { Collinearity } \\
\text { Statistics }\end{array}$} \\
\hline & $B$ & $\begin{array}{l}\text { Std. } \\
\text { Error }\end{array}$ & & & & $\begin{array}{l}\text { Zero- } \\
\text { order }\end{array}$ & $\begin{array}{c}\text { Parti } \\
\text { al }\end{array}$ & Part & $\begin{array}{c}\text { Tolera } \\
\text { nce }\end{array}$ & VIF \\
\hline (Constant) & 4,190 & 1,560 & & 2,687 & 0,010 & & & & & \\
\hline $\begin{array}{l}\text { Karakteristik } \\
\text { Pekerjaan }\end{array}$ & 0,457 & 0,129 & 0,253 & 3,539 & 0,001 & 0,703 & 0,444 & 0,191 & 0,570 & 1,755 \\
\hline 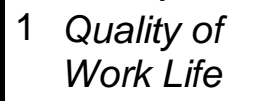 & 0,913 & 0,169 & 0,427 & 5,388 & 0,000 & 0,830 & 0,602 & 0,291 & 0,464 & 2,156 \\
\hline $\begin{array}{l}\text { Kepuasan } \\
\text { Kerja }\end{array}$ & 0,491 & 0,077 & 0,418 & 6,379 & 0,000 & 0,763 & 0,666 & 0,344 & 0,677 & 1,477 \\
\hline
\end{tabular}

a. Dependent Variable: Organizational Citizenship Behavior (OCB)

Hasil persamaan regresi berganda adalah $=$

Dari persamaan regresi berikut dapat dijelaskan bahwa

$$
\begin{aligned}
& Y=\alpha+b_{1} X_{1}+b_{2} X_{2}+b_{3} X_{3} \\
& Y=4,190+0,457 X^{1}+0,913 X 2+0,491 X^{3}
\end{aligned}
$$

1) $\mathrm{a}=4,190$ adalah bilangan konstanta yang berarti apabila variabel $X_{1}, X_{2}$ dan $X_{3}=0$, maka konstanta Organizational Citizenship Behavior (OCB) adalah sebesar 4,190. 
2) $b_{1}=0,457$ Ini berarti bahwa $X_{1}$ berpengaruh positif terhadap Organizational Citizenship Bahavior (OCB) di PT Djasa Bahari di Surabaya, atau dengan kata lain jika variabel Karakteristik Pekerjaan $\left(X_{1}\right)$ ditingkatkan sebesar satu satuan, maka Organizational Citizenship Behavior (OCB) bertambah sebesar 0,547. dengan asumsi variabel lain yang mempengaruhi dianggap kostan $\left(\mathrm{a}, \mathrm{X}_{1}=0\right)$.

3) $b_{2}=$ koefesiensi untuk variabel Quality of Work Life adalah sebesar 0,913, hal ini berarti bahwa variabel Quality of Work $\left(\mathrm{X}_{2}\right)$ berpengaruh positif terhadap Organizational Citizenship Behavior (OCB) atau dengan kata lain jika variabel Quality of Work Life $\left(X_{2}\right)$ ditingkatkan satu satuan, maka Organizational Citizenship Behavior (OCB) bertambah sebesar 0,913. dengan asumsi variabel lain yang mempengaruhi dianggap kostan $\left(\mathrm{a}, \mathrm{X}_{2}=0\right)$.

4) $b_{3}=$ koefesiensi untuk variabel kepuasan kerja adalah sebesar 0,41 , hal ini berarti bahwa variabel Kepuasan Kerja $\left(X_{3}\right)$ berpengaruh positif terhadap Organizational Citizenship Behavior (OCB) atau dengan kata lain jika variabel Kepuasan Kerja $\left(\mathrm{X}_{3}\right)$ ditingkatkan satu satuan, maka Organizational Citizenship Behavior (OCB) bertambah sebesar 0,491. dengan asumsi variabel lain yang mempengaruhi dianggap kostan $\left(a, X_{3}=0\right)$.

5) Dari hasil penjelasan diatas dapat disimpulkan bahwa dari hasil uji regresi linear berganda faktor yang paling dominan adalah Quality of Work Life $\left(\mathrm{X}_{2}\right)$ dengan koefesien regresi sebesar 0,913 atau $91 \%$, disusul oleh karakteristik pekerjaan $\left(X_{1}\right)$ sebesar 0,457 dan Kepuasan Kerja $\left(X_{3}\right)$ sebesar 0,491.

\section{Uji T (Parsial)}

Tabel 3

Uji T (Parsial)

Coefficients $^{\mathrm{a}}$

\begin{tabular}{|c|c|c|c|c|c|c|c|c|c|c|}
\hline \multirow[t]{2}{*}{ Model } & \multicolumn{2}{|c|}{$\begin{array}{l}\text { Unstandard } \\
\text { ized } \\
\text { Coefficients }\end{array}$} & \multirow{2}{*}{$\begin{array}{c}\text { Standar } \\
\text { dized } \\
\text { Coeffici } \\
\text { ents } \\
\text { Beta }\end{array}$} & \multirow[t]{2}{*}{$\mathrm{T}$} & \multirow[t]{2}{*}{ Sig. } & \multicolumn{3}{|c|}{ Correlations } & \multicolumn{2}{|c|}{$\begin{array}{l}\text { Collinearity } \\
\text { Statistics }\end{array}$} \\
\hline & $B$ & $\begin{array}{l}\text { Std. } \\
\text { Error }\end{array}$ & & & & $\begin{array}{c}\text { Zero } \\
- \\
\text { order }\end{array}$ & $\begin{array}{l}\text { Parti } \\
\text { al }\end{array}$ & Part & $\begin{array}{c}\text { Tolera } \\
\text { nce }\end{array}$ & VIF \\
\hline (Constant) & $\begin{array}{r}4,19 \\
0\end{array}$ & $\begin{array}{r}1,56 \\
0\end{array}$ & & $\begin{array}{r}2,68 \\
7\end{array}$ & $\begin{array}{r}0,01 \\
0\end{array}$ & & & & & \\
\hline $\begin{array}{l}\text { Karakteristik } \\
\text { Pekerjaan }\end{array}$ & $\begin{array}{r}0,45 \\
7\end{array}$ & $\begin{array}{r}0,12 \\
9\end{array}$ & 0,253 & $\begin{array}{r}3,53 \\
9\end{array}$ & $\begin{array}{r}0,00 \\
1\end{array}$ & $\begin{array}{r}0,70 \\
3\end{array}$ & $\begin{array}{r}0,44 \\
4\end{array}$ & $\begin{array}{r}0,19 \\
1\end{array}$ & 0,570 & $\begin{array}{r}1,75 \\
5\end{array}$ \\
\hline
\end{tabular}




\begin{tabular}{|l|r|r|r|r|r|r|r|r|r|r|}
\hline Quality of & 0,91 & 0,16 & 0,427 & 5,38 & 0,00 & 0,83 & 0,60 & 0,29 & 0,464 & 2,15 \\
Work Life & 3 & 9 & & 8 & 0 & 0 & 2 & 1 & & 6 \\
Kepuasan & 0,49 & 0,07 & 0,418 & 6,37 & 0,00 & 0,76 & 0,66 & 0,34 & 0,677 & 1,47 \\
Kerja & 1 & 7 & & 9 & 0 & 3 & 6 & 4 & & 7 \\
\hline
\end{tabular}

a. Dependent Variable: Organizational Citizenship Bahavior (OCB)

Dari tabel 3 diketahui nilai t hitung adalah lebih besar dari $\mathrm{t}$ tabel yaitu 2,007 sehingga dapat diketahui bahwasanya terdapat pengaruh positif dan signifikan antara variabel disimpulkan bahwasanya terdapat pengaruh yang positif dan signifikan dari Karakteristik Pekerjaan, Quality of Work Life dan Kepuasan Kerja Terhadap Organizational Citizenship Behavior (OCB) secara parsial, nilai probabilitas 0,000. Maka hipotesis dalam penelitian ini dapat diterima. Dari hasil uji $\mathrm{t}$ diperoleh $\mathrm{t}$ hitung 3,539 lebih besar dari t tabel 2,007, sehingga $t$ hitung $\geq t$ tabel maka Ho ditolak, yang berarti ada yang pengaruh signifikan antara variabel $\mathrm{X}_{1}$ (Karakteristik Pekerjaan), $\mathrm{X}_{2}$ (Quality of Work Life), Kepuasan Kerja dengan variabel Y (Organizational Citizenship Behavior). Dari hasil uji t diperoleh $\mathrm{t}$ hitung 5,388 lebih besar dari t tabel 2,007, sehingga $t$ hitung $\geq \mathrm{t}$ tabel maka Ho ditolak, yang berarti ada pengaruh signifikan antara variabel $\mathrm{X}_{2}$ (Quality of Work Life) dengan variabel Y (Organizational Citizenship Behavior). Dari hasil uji t diperoleh t hitung 6,379 lebih besar dari t tabel 2,007, sehingga t hitung $\geq t$ tabel maka Ho ditolak, yang berarti ada yang pengaruh signifikan antara variabel $\mathrm{X}_{3}$ (Kepuasan Kerja) dengan variabel Y (Organizational Citizenship Behavior).

\section{Uji F (Simultan)}

Tabel 4

\section{Uji F (Simultan)}

ANOVA $^{\text {a }}$

\begin{tabular}{|rl|r|r|r|r|r|}
\hline Model & \multicolumn{1}{c|}{$\begin{array}{c}\text { Sum of } \\
\text { Squares }\end{array}$} & \multicolumn{1}{c|}{$\mathrm{df}$} & Mean Square & $\mathrm{F}$ & Sig. \\
\hline \multirow{2}{*}{1} & Regression & 464,188 & 3 & 154,729 & 97,408 & 0,00 \\
& & & & & & $0^{\mathrm{b}}$ \\
& Residual & 81,012 & 51 & 1,588 & & \\
& Total & 545,200 & 54 & & & \\
\hline
\end{tabular}

a. Dependent Variable: Organizational Citizenship Behavior

b. Predictors: (Constant), Karakteristik Pekerjaan, Quality of Work, Kepuasan Kerja

Dari tabel 4 dapat diketahui nilai $F_{\text {tabel }}$ sebesar 3,18 dengan nilai probabilitas 0,000 . Apabila nilai $F_{\text {hitung dibandingkan dengan } F_{\text {tabel }}}$ maka nilai $F$ hitung lebih besar dibandingkan dengan nilai $F$ tabel pada penelitian yaitu dengan hasil 97,408 sehingga Ho dotolak dan Ha diterima. dapat disimpulkan bahwasanya terdapat pengaruh yang positif dan signifikan dari Karakteristik Pekerjaan, Quality of Work Life dan Kepuasan Kerja terhadap Organizational Citizenship Behavior dengan demikian hipotesis dalam penelitian ini dapat diterima. 


\section{Koefisien Determinasi}

Tabel 5.9

Uji Koefisien Determinasi $\mathbf{R}^{2}$ Model Summary ${ }^{\mathrm{b}}$

\begin{tabular}{|c|c|c|c|c|c|c|c|c|c|}
\hline \multirow{2}{*}{$\begin{array}{l}\text { Mod } \\
\text { el }\end{array}$} & \multirow[t]{2}{*}{$\mathrm{R}$} & \multirow{2}{*}{$\begin{array}{c}\mathrm{R} \\
\text { Squar } \\
\mathrm{e}\end{array}$} & \multirow{2}{*}{$\begin{array}{l}\text { Adjuste } \\
d R \\
\text { Square }\end{array}$} & \multirow[b]{2}{*}{$\begin{array}{l}\text { Std. } \\
\text { Error of } \\
\text { the } \\
\text { Estimat } \\
\text { e }\end{array}$} & \multicolumn{5}{|c|}{ Change Statistics } \\
\hline & & & & & $\begin{array}{c}\mathrm{R} \\
\text { Square } \\
\text { Change }\end{array}$ & $\begin{array}{c}\text { F } \\
\text { Cha } \\
\text { nge }\end{array}$ & df1 & $\mathrm{df2}$ & $\begin{array}{l}\text { Sig. F } \\
\text { Change }\end{array}$ \\
\hline 1 & $\begin{array}{r}0,92 \\
3^{\mathrm{a}}\end{array}$ & 0,851 & 0,843 & 1,260 & 0,851 & $\begin{array}{r}97,4 \\
08\end{array}$ & 3 & 51 & 0,000 \\
\hline
\end{tabular}

a. Predictors: (Constant), Karakteristik Pekerjaan, Quality of Work Life, Kepuasan Kerja

b. Dependent Variable: Organizational Citizenship Behavior

Berdasarkan dari data hasil perhitungan analisis regresi pada tabel di atas diperoleh nilai $\mathrm{R}^{2}$ ( $R$ Square) sebesar 0,851 yang berarti 95\%. Hal ini menunjukkan bahwa prosentase sumbangan pengaruh variabel independen (Karakteristik Pekerjaan, Quality of Work Life dan Kepuasan Kerja terhadap variabel dependen Organizational Citizenship Behavior adalah 95\% sedangkan 5\% dipengaruhi oleh faktor lain.

\section{KESIMPULAN}

Berdasarkan hasil penelitian didapatkan kesimpulan sebagai berikut:

1. Berdasarkan uji $t$ secara Parsial yaitu variabeL Karakteristik Pekerjaan $\left(\mathrm{X}_{1}\right)$, Quality of Work $\left(\mathrm{X}_{2}\right)$ dan Kepuasan Kerja $\left(\mathrm{X}_{3}\right)$ dan Variabl Y (Organizational Citizenship Behavior). Dari ketiga variabel $X$ mempunyai pengaruh yang signifikan secara Parsial terhadap Variabel Y.

2. Berdasarkan uji $F$ simultan maka dapat disimpulkan bahwa semua variabel $X$ ada pengaruh yang signifikan secara simultan terhadap variabel Y (Organizational Citizenship Behavior) Berdasarkan hasil penelitian pada koefisien regresi linier berganda maka dapat diketahui bahwa variabel yang paling dominan adalan Variabel X2 yaitu Quality of Work Life

\section{DAFTAR PUSTAKA}

Bowling, N.A., Wang, Q., Li, H.Y. (2010). The Moderating Effect of Core Self Evaluations on the Relationships Between Job Attitudes and Organisational Citizenship Behavior. Applied Psychology, 61(1), pp.97-113

Hackman, J. R., \& Oldham, G. R. (1976). Motivation through the design of work: test Of a theory. Organizational Behavior and Human Performance, 16(2), 250-279. 
Ju, Yoon-Hwang., Cho, Hee-Young., \& Yang, Hoe-Chang (2013). The Impact of New Silver-Generation Consumer's Perceived Quality of Service and the Service Provider's Organizational

Kaskel, R. J. (2000). Value congruence and satisfaction.Unpublisheddoctoraldissertation. The California School Of Professional Psychology At Alameda.

Kreitner, Robert and Angelo Kinicki. 2005. Perilaku Organisasi (Organisazional Citizenship CJBehaviour). Jakarta : Salemba Empat.

Nanggoy, S. \& Harianti, R. (2005). "Pengaruh Kepuasan Kerja Karyawan Terhadap Turnover Intentions di PT. Andalan Pacific Samudera di Surabaya" (Skripsi No.05011881/MAN/2005).

Podsakoff, P. M., MacKenzie, S. B., Paine, J. B., Bachrach, D.G. (2000). Organizational citizenship behaviors: A critical review of the theoretical and empirical literature and suggestions for future research. Journal of Management, Vol. 26, No. 3, pp.513-563.

Robbins, S. \& Judge, T. 2007. Organizational Behavior, 12th edition. New York:Prentice Hall.

Sirgy, M. J. Efraty, D. Siegel, P. and Lee, D. 2001. "A New Measure of Quality of Work Life (QWL) Based on Need Satisfaction and Spillover Theory,". Social Indicators Research. Vol.55, pp: 241-302

Sugiyono. 2017. Metode Penelitian Bisnis. Bandung: Alfabeta.

Syahbanuari dan Abdurrahman. 2019. Pengaruh Quality Of Work Life (QWL) dan Komitmen Organisasi terhadap Organizational Citizenship Behavior (OCB) The Influence Of Quality Of Work Life (QWL) And Organizational Commitment To The Organizational Citizenship Behavior (OCB)(A Study on Regular Employee of PT Pindad PERSERO) Prosiding manajemen vol 5 No 12019

Smith, C.A., Organ, D. W. ve Near, J. P. 1983. Organizational Citizenship Behavior: Its Nature and Antecedents, Journal of Applied Psychology, (68) 653-663.

Organ, D.W., Lingl, A. (1995). Personality, Satisfaction, and Organizational Citizenship Behavior. The Journal of Social Psychology. 135:3, pp.339-350

Wagner, S., Rush, M. 2000. Altruistic organizational citizenship behavior: context, disposition and age, The Journal of Social Psychology, 140, 379-91.

Yeşilyurt, H. veKoçak, N. 2014. İş Doyumuve Örgütsel Vatandaşlık Davranışı Arasındakillişkinin Otellişletm Ler Açısından İncelenmesi, Dokuz Eylül Üniversitesi, Sosyal Bilimler Enstitüsü Dergisi, 16(2), 303324. 